\title{
The diabetic pregnancy and offspring blood pressure in childhood: a systematic review and meta-analysis
}

\author{
A. Aceti - S. Santhakumaran - K. M. Logan - L. H. Philipps • \\ E. Prior • C. Gale • M. J. Hyde • N. Modi
}

Received: 1 May 2012 / Accepted: 10 July 2012 / Published online: 5 September 2012

(C) Springer-Verlag 2012

\begin{abstract}
Aims/hypothesis Offspring of diabetic mothers have increased risk of the metabolic syndrome in adulthood. Studies examining BP in offspring of diabetic mothers have conflicting conclusions. We performed a systematic review and metaanalysis of studies reporting offspring BP in children born to diabetic mothers.

Methods Citations were identified in PubMed. Authors were contacted for additional data. Systolic and diastolic BP in offspring of diabetic mothers and controls were compared. Subgroup analysis of type of maternal diabetes and offspring sex were performed. Fixed-effects models were used, and random-effects models where significant heterogeneity was present. Meta-regression was used to test the relationship between offspring systolic BP and prepregnancy BMI.

Results Fifteen studies were included in the review and 13 in the meta-analysis. Systolic BP was higher in offspring of diabetic mothers (mean difference $1.88 \mathrm{mmHg}$ [95\% CI 0.47 , 3.28]; $p=0.009$ ). Offspring of mothers with gestational diabetes had similar diastolic BP to controls, but higher systolic BP (1.39 $\mathrm{mmHg}$ [95\% CI 0.00, 2.77]; $p=0.05)$; results for type 1 diabetes were inconclusive and there were no separate data available on offspring of type 2 diabetic mothers. Male offspring of diabetic mothers had higher systolic BP $(2.01 \mathrm{mmHg}$ [95\% CI 0.93, 3.10]; $p=0.0003)$ and diastolic BP $(1.12 \mathrm{mmHg}$ [95\% CI 0.36, 1.88]; $p=0.004)$ than controls; in female offspring there was no difference (systolic: $0.54 \mathrm{mmHg}$
\end{abstract}

Electronic supplementary material The online version of this article (doi:10.1007/s00125-012-2689-8) contains peer-reviewed but unedited supplementary material, which is available to authorised users.

A. Aceti - S. Santhakumaran - K. M. Logan • L. H. Philipps •

E. Prior $\cdot$ C. Gale $\cdot$ M. J. Hyde $\cdot$ N. Modi $(\square)$

Section of Neonatal Medicine, Department of Medicine,

Imperial College London,

Chelsea and Westminster Campus, 369 Fulham Road,

London SW10 9NH, UK

e-mail:n.modi@imperial.ac.uk
[95\% CI $-1.83,2.90], p=0.66$; diastolic: $0.51 \mathrm{mmHg}$ [95\% CI -1.07, 2.09], $p=0.52$ ). The correlation between offspring systolic BP and maternal prepregnancy BMI was not significant $(p=0.37)$.

Conclusions/interpretation Offspring of diabetic mothers have higher systolic BP than controls. Differences related to sex and type of maternal diabetes require further investigation.

Keywords Blood pressure · Diabetes · Gestational diabetes · Infant $\cdot$ Maternal diabetes $\cdot$ Meta-analysis $\cdot$ Offspring of diabetic pregnancy $\cdot$ Pregnancy $\cdot$ Systematic review
Abbreviations
DBP Diastolic BP
GDM Gestational diabetes mellitus
MeSH Medline subject heading
ODM Offspring of diabetic mothers
SBP Systolic BP

\section{Introduction}

Diabetes is a common pregnancy complication, affecting up to $5 \%$ of pregnancies in the UK. Approximately $87.5 \%$ of diabetic pregnancies are due to gestational diabetes (GDM), $7.5 \%$ to type 1 diabetes, and $5 \%$ to pre-existing type 2 diabetes [1]. The prevalence of diabetic pregnancies is also rising. Between 1996 and 2004, the number of pregnancies complicated by pre-existing diabetes increased by $50 \%$, and the prevalence of GDM doubled [2, 3].

Diabetes during pregnancy is associated with short-term $[4,5]$ and long-term [6] adverse offspring outcomes. The concept that intrauterine exposure to diabetes 'programmes' long-term offspring health was postulated by Freinkel and Metzger as 'fuel-mediated teratogenesis' in 1980 [7, 8]. Offspring of diabetic mothers (ODM) have a higher rate of 
diabetes and features of the metabolic syndrome [6], both strongly associated with premature death [9].

Studies in Pima Indians show that intrauterine exposure to diabetes is an independent risk factor, additional to genetic predisposition, for the development of diabetes and features of the metabolic syndrome, including increased BP $[10,11]$. However, the strength of the association between diabetes during pregnancy and offspring BP is unclear, as studies to date have been small and of limited power.

The primary aim of this systematic review and metaanalysis was to establish the impact of maternal diabetes on offspring BP. Secondary objectives were to distinguish the effect of type of maternal diabetes and offspring sex on offspring BP, as the risks of hypertension and cardiovascular disease have sex-specific features [12], and to investigate the role of maternal prepregnancy BMI in the relationship between maternal diabetes and offspring BP.

\section{Methods}

\section{Literature search}

A systematic review of published studies reporting BP in offspring of diabetic and non-diabetic pregnancies was undertaken following the MOOSE guidelines for systematic reviews of observational studies [13]. All types of maternal diabetes mellitus (prepregnancy type 1 diabetes and type 2 diabetes and GDM) were considered as exposures. An unselected non-diabetic control group must have been reported within the same study to be included in the review. The inclusion criterion for offspring was age between 2 and 18 years at the time of BP assessment.

A search was conducted in PubMed (www.ncbi.nlm.nih. gov) for studies published before 14 February 2012, using Medline subject heading (MeSH) keywords: (Pregnancy in diabetics OR Diabetes, gestational) and (Prenatal exposure delayed effects OR Child) and (Blood pressure). The review was limited to human studies. Review articles were excluded after reference lists had been searched. The search was conducted by MJH, LHP and EP; relevant studies were identified from the abstract or the full paper if no abstract was available. Reference lists of papers retrieved were searched for further studies; attempts were made to trace forward citations. In studies where BP was mentioned in the paper but not published, and in studies not reporting $\mathrm{BP}$ as mean $\pm \mathrm{SD}, \mathrm{MJH}$ and $\mathrm{AA}$ contacted the authors for relevant data. If no response was received after two requests, or if the author was unable to provide data, the study was excluded from the meta-analysis. Where multiple papers published the same cohort, only the one reporting outcomes at the age closest to the median age of the studies overall was included.
Data extraction and analysis

Information on individual study populations, exposure, outcome, results and covariates were independently extracted by LHP and MJH and checked by AA and KL. Study quality was examined independently by AA, CG and MJH using a modified Newcastle-Ottawa Quality Assessment Scale [14] (electronic supplementary material [ESM] Fig. 1).

The association between diabetes during pregnancy and offspring systolic BP (SBP) and diastolic BP (DBP) was examined by meta-analyses, conducted by AA, LHP, SS and MJH in RevMan 5 (5.0.24) (http://ims.cochrane.org/revman/ download) using the inverse variance method. Subgroup analyses according to type of maternal diabetes (type 1 diabetes and GDM) and offspring sex were carried out. Differences between subgroups were tested for significance using metaregression: each type-specific result was treated as one study, and robust variance estimation with hierarchical weights was used to allow for dependencies between type-specific results from the same study [15]. Where studies only reported data for different types of diabetes, pooled means and SD were calculated for all diabetes types combined.

A fixed-effects meta-analysis was carried out for all comparisons. Heterogeneity was assessed using the $\chi^{2}$ test on Cochran's Q statistic [16] and by calculating $I^{2}$, the estimated proportion of variability due to differences between studies [17]. If significant heterogeneity was present ( $p<0.05$ from the $\chi^{2}$ test), a random-effects meta-analysis was carried out. Both the fixed- and random-effects results are presented [18]. Because the test for heterogeneity is known to have low power when the number of studies is small [19], when heterogeneity was not significant but the number of studies was five or fewer, a random-effects analysis was additionally performed to check the sensitivity of the conclusions.

Potential sources of heterogeneity were investigated. A meta-analysis restricted to studies with a high Modified Newcastle-Ottawa score ( $\geq 5$ out of 7 ) was carried out to check whether conclusions remained the same when only high-quality studies were analysed. Where studies provided adjusted results, a separate metaanalysis was carried out; for these studies, a metaanalysis of the unadjusted data was also carried out to check whether any differences were due to a subgroup effect rather than the adjustment for confounders. To evaluate the effect of maternal prepregnancy BMI on offspring BP, the mean difference in maternal prepregnancy BMI between cases and controls was calculated for each individual study and was plotted against the mean difference in offspring SBP. A meta-regression was carried out to see if the studies with larger differences in maternal BMI had larger differences in offspring BP. 
Forest plots were used to illustrate results from metaanalyses, and funnel plots to investigate bias. The pooled result from a fixed-effects analysis was used as the reference line for the funnel plot, as the random-effects result is more affected by publication bias making visual detection difficult [20]. If funnel plots showed asymmetry, Egger's test was performed [21]. Differences between groups are shown as the pooled estimated mean difference $(95 \% \mathrm{CI})$ unless otherwise stated.

\section{Results}

Literature search

The literature search identified 94 papers, of which 19 matched the inclusion criteria [11, 22-39] (Fig. 1). Three additional studies [40-42] were identified from the

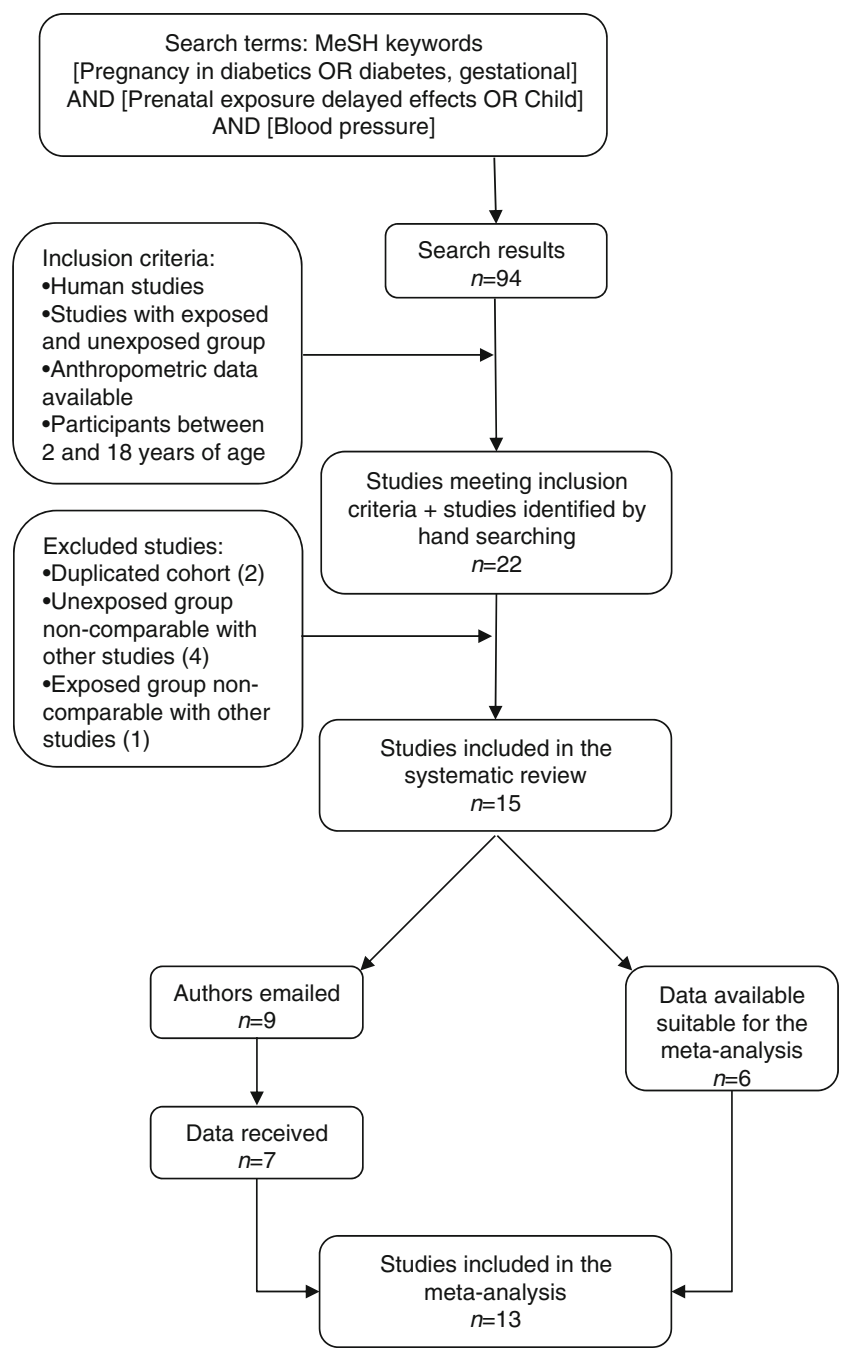

Fig. 1 Flow chart of the search strategy used in this review. The relevant number of papers at each point is given reference lists of included papers, giving 22 papers in total. Two cohorts were reported twice; two papers were excluded on this basis [35, 37]. Four studies were excluded because the control groups were not comparable to other studies (offspring of mothers who subsequently developed diabetes [11, 23, 27], and offspring of mothers with impaired glucose tolerance during pregnancy [31]). One study was excluded because the study population (preterm, low-birthweight infants [22]) was not comparable to other studies.

Fifteen papers remained for inclusion in the review. Two papers mentioned BP, but reported no data [26, 41]; the authors were contacted, but were unable to provide the data. Where outcome data were not represented as unadjusted mean and SD [24, 30, 33, 34, 36, $38,42]$, the authors were contacted; data were received for all studies.

Final data for inclusion in the meta-analysis were available from 13 studies for SBP [24, 25, 28-30, 32-34, 36, $38-40,42]$ and 12 studies for DBP [24, 25, 28-30, 32-34, $36,38,40,42]$. All were cohort studies (ten prospective, three retrospective). The median age of offspring at assessment was 8 years.

Seven studies provided BP in offspring of mothers with GDM [24, 25, 29, 34, 36, 39, 40], and two in offspring of mothers with type 1 diabetes [32, 33]. Four studies included pooled outcome data for offspring of both type 1 diabetes and GDM mothers [28, 30, 38, 42]; one study included data from prepregnancy type 2 diabetes in their pooled diabetic group [28]; authors provided separate data for type 1 diabetes and GDM for three studies [30, 38, 42]. No study reported separate outcomes for offspring of prepregnancy type 2 diabetes.

One study provided sex-specific data for offspring BP [29]; authors of all included studies were contacted, and sexspecific data were provided for eight further studies [24, 30, 33, 34, 36, 38, 40, 42]. Five studies reported maternal prepregnancy BMI $[25,30,36,39,40]$, and two studies reported offspring SBP data adjusted for prepregnancy maternal BMI $[38,39]$. A description of studies included is provided in Table 1. When heterogeneity was present in the fixed-effects analysis and the random-effects analysis was performed, the results for the fixed-effects analysis are provided in Table 2.

Offspring blood pressure

Thirteen studies provided data on SBP in ODM, and 12 studies on DBP. SBP was higher in ODM than in controls $(1.88 \mathrm{mmHg}$ [95\% CI 0.47, 3.28]; $p=0.009$; random-effects analysis; Fig. 2a). DBP was not significantly different between ODM and controls $(0.74 \mathrm{mmHg}$ [95\% CI $-0.14,1.62] ; p=0.10$; random-effects analysis; Fig. 2b). 


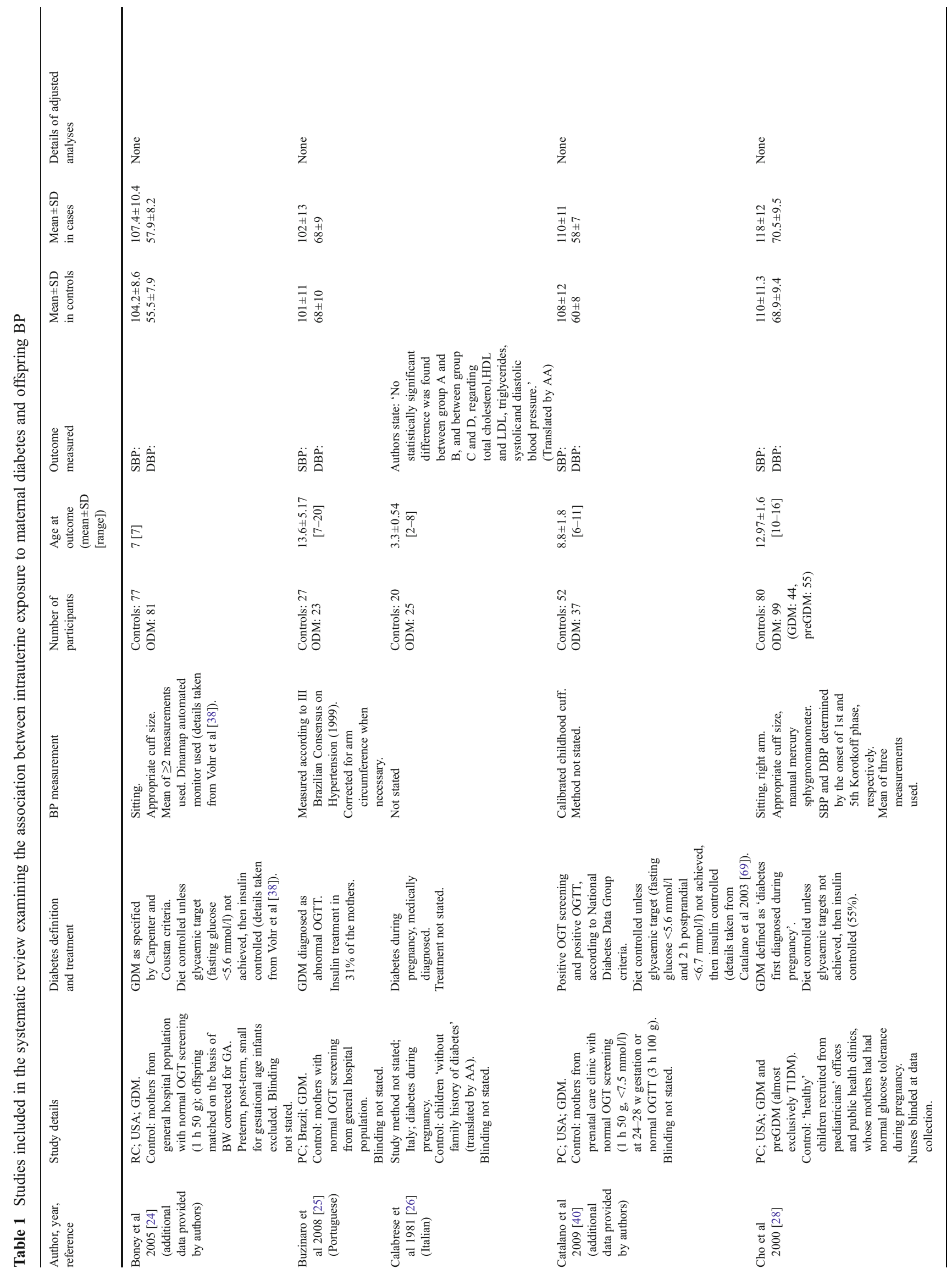




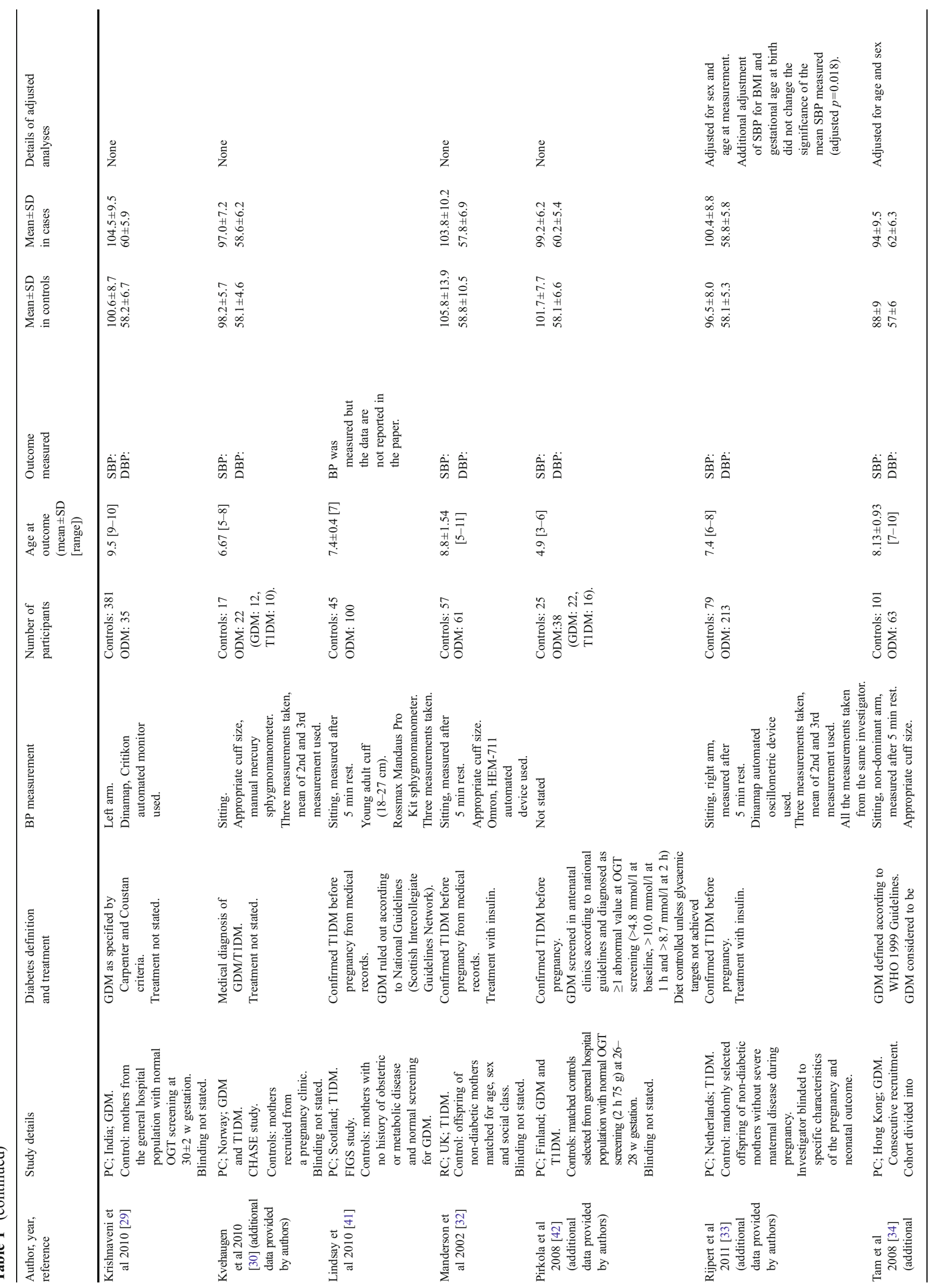




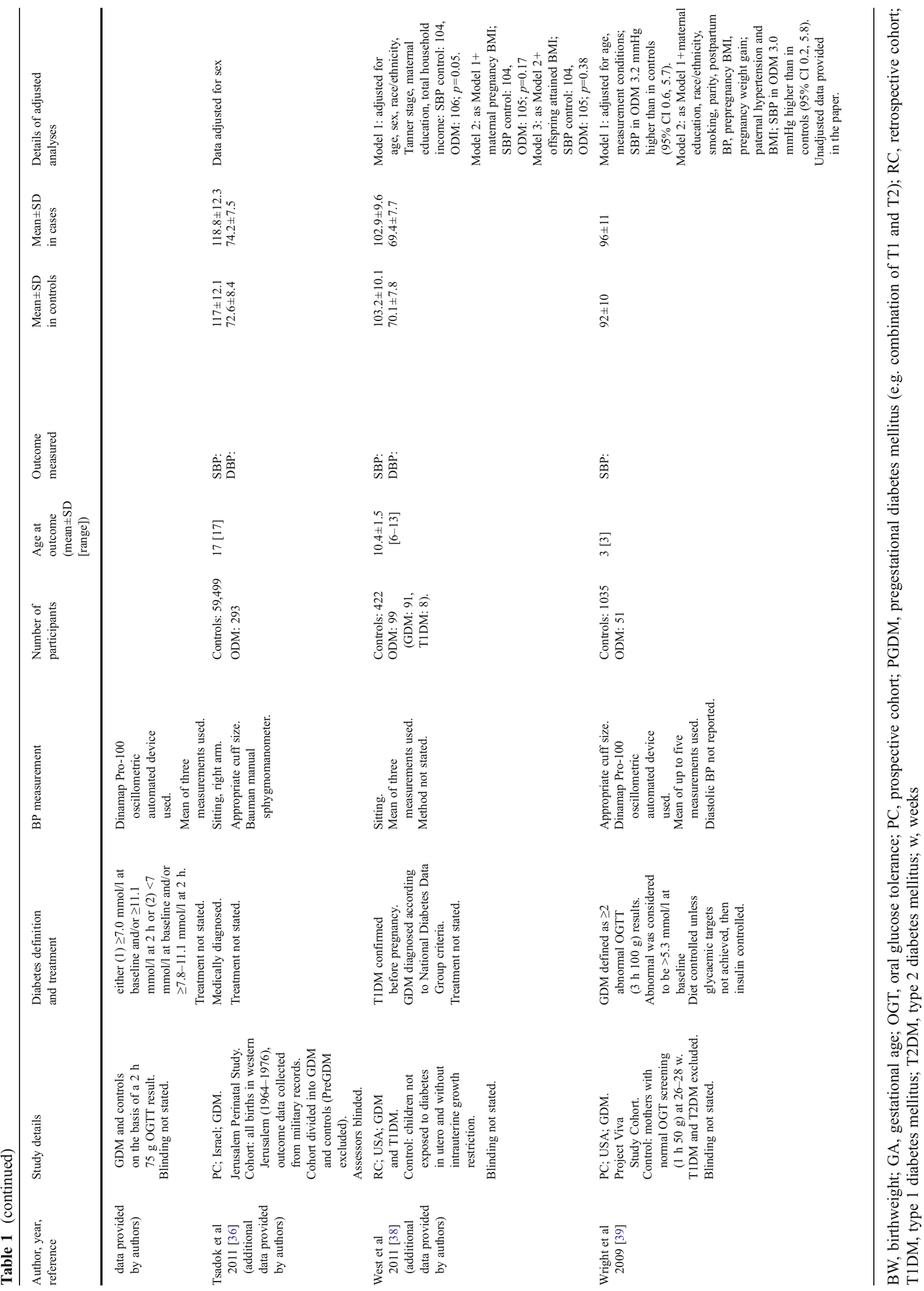


Table 2 Mean difference in SBP and DBP between ODM and controls with fixed effects analysis

\begin{tabular}{|c|c|c|c|c|c|c|c|}
\hline \multirow[t]{2}{*}{ Outcome } & \multirow[t]{2}{*}{ Cohort } & \multirow{2}{*}{$\begin{array}{l}\text { Number } \\
\text { of studies }\end{array}$} & \multirow{2}{*}{$\begin{array}{l}\text { Number of } \\
\text { participants }\end{array}$} & \multirow{2}{*}{$\begin{array}{l}\text { Mean difference } \\
(95 \% \mathrm{CI}) \text { in } \mathrm{BP} \\
(\mathrm{mmHg})\end{array}$} & \multirow[t]{2}{*}{$p$ value } & \multicolumn{2}{|c|}{ Heterogeneity } \\
\hline & & & & & & $I^{2}$ & $p$ value \\
\hline SBP & $\begin{array}{l}\text { All types of diabetes } \\
\text { combined }\end{array}$ & 13 & $\begin{array}{l}\text { ODM: } 1,115 \\
\text { Controls: } 61,852\end{array}$ & $1.96(1.20,2.72)$ & $<0.00001$ & $64 \%$ & 0.0009 \\
\hline DBP & $\begin{array}{l}\text { All types of diabetes } \\
\text { combined }\end{array}$ & 12 & $\begin{array}{l}\text { ODM: } 1,064 \\
\text { Controls: } 60,817\end{array}$ & $1.01(0.48,1.55)$ & 0.0002 & $50 \%$ & 0.02 \\
\hline SBP & GDM & 10 & $\begin{array}{l}\text { ODM: } 708 \\
\text { Controls: } 61,636\end{array}$ & $1.48(0.59,2.36)$ & 0.001 & $48 \%$ & 0.04 \\
\hline DBP & GDM & 9 & $\begin{array}{l}\text { ODM: } 657 \\
\text { Controls: } 60,601\end{array}$ & $1.19(0.57,1.80)$ & 0.0001 & $62 \%$ & 0.006 \\
\hline SBP & Female & 9 & $\begin{array}{l}\text { ODM: } 429 \\
\text { Controls: } 23,203\end{array}$ & $1.01(-0.19,2.22)$ & 0.10 & $70 \%$ & 0.0007 \\
\hline DBP & Female & 9 & $\begin{array}{l}\text { ODM: } 429 \\
\text { Controls: } 23,203\end{array}$ & $0.88(0.09,1.67)$ & 0.003 & $70 \%$ & 0.0009 \\
\hline SBP & $\begin{array}{l}\text { Data adjusted for } \\
\text { covariates including } \\
\text { offspring age and sex }\end{array}$ & 5 & $\begin{array}{l}\text { ODM: } 719 \\
\text { Controls: } 61,137\end{array}$ & $1.80(0.92,2.67)$ & $<0.0001$ & $59 \%$ & 0.04 \\
\hline DBP & $\begin{array}{l}\text { Data adjusted for } \\
\text { covariates including } \\
\text { offspring age and sex }\end{array}$ & 3 & $\begin{array}{l}\text { ODM: } 569 \\
\text { Controls: } 59,680\end{array}$ & $0.11(-0.99,1.20)$ & 0.85 & $85 \%$ & 0.001 \\
\hline
\end{tabular}

There was no clear visual evidence of asymmetry from the funnel plot for SBP (ESM Fig. 2a). The funnel plot for DBP appeared slightly asymmetric (ESM Fig. 2b); studies with the largest standard errors showed an effect in the opposite direction to the pooled results. However, Egger's test was not significant for either SBP $(p=0.78)$ or DBP $(p=0.21)$.

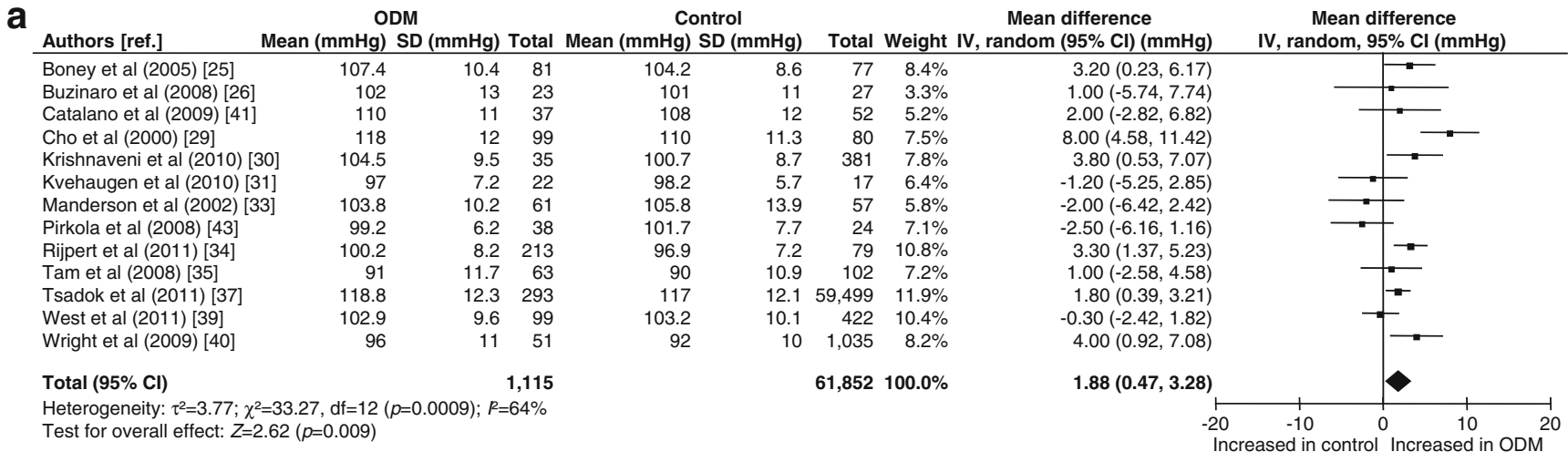

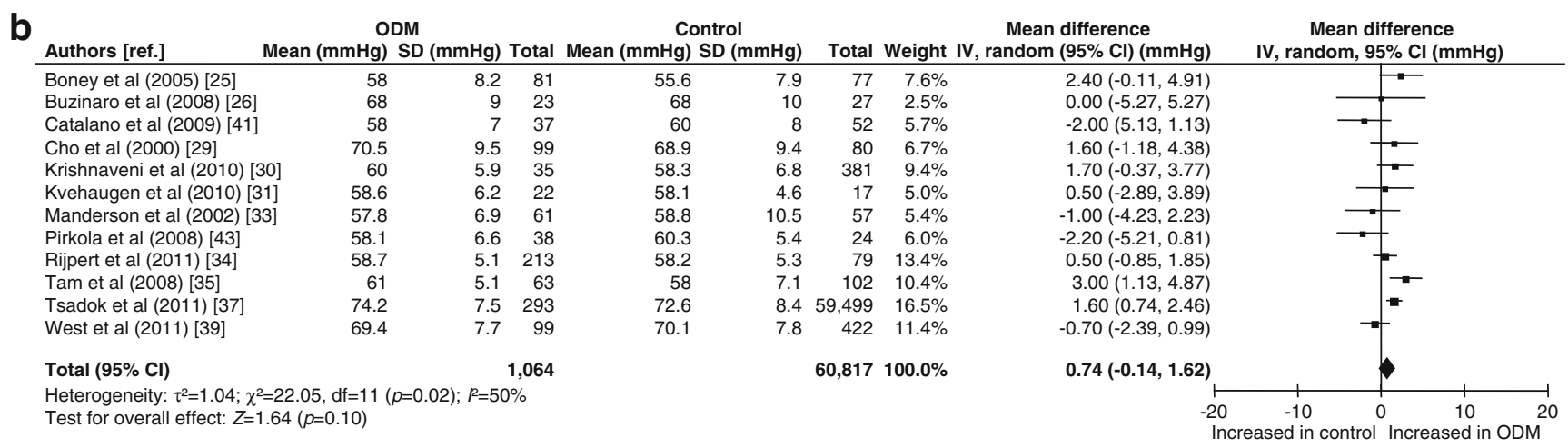

Fig. 2 Forest plot showing the unadjusted association between all types of maternal diabetes and offspring BP. (a) SBP; (b) DBP. IV, inverse variance 
Subgroup analyses

\section{Type of maternal diabetes}

(1) Gestational diabetes (ten studies SBP, nine studies DBP)

SBP was higher in offspring of mothers with GDM (1.39 mmHg [95\% CI 0.00, 2.77]; $p=0.05$; random-effects analysis; Fig. 3a) than controls. There was no significant difference in DBP $(0.75 \mathrm{mmHg}$ [95\% CI $-0.47,1.97] ; p=0.23$; random-effects analysis; Fig. 3b).

(2) Type 1 diabetes mellitus (five studies)

SBP was higher in offspring of mothers with type 1 diabetes $(1.64 \mathrm{mmHg}$ [95\% CI $0.09,3.18] ; p=0.04$; fixed-effect analysis; Fig. 4a) than controls. No significant difference was shown in DBP $(0.10 \mathrm{mmHg}[95 \%$ CI $-1.03,1.23] ; p=0.86$; fixed-effect analysis; Fig. $4 \mathrm{~b}$ ). As there were only five studies in this subgroup, randomeffects analyses were also performed (SBP: $0.25[95 \%$ CI $-2.55,3.04] ; p=0.86$; DBP: 0.10 [95\% CI $-1.03,1.23]$; $p=0.86$ ).

As the results regarding type 1 diabetes were inconclusive, meta-regression was not performed.
Offspring sex (nine studies)

\section{(1) SBP}

There was no difference in SBP between female ODM and controls $(0.54 \mathrm{mmHg}$ [95\% CI -1.83 , 2.90]; $p=0.66$; random-effects analysis; Fig. 5a). SBP in male ODM was higher than in controls $(2.01 \mathrm{mmHg}$ [95\% CI $0.93,3.10]$; $p=0.0003$; fixed-effect analysis; Fig. 5b).

\section{(2) DBP}

There was no difference in DBP between female ODM and controls $(0.51 \mathrm{mmHg}$ [95\% CI $-1.07,2.09] ; p=0.52$; random-effects analysis; Fig. 6a). DBP in male ODM was higher than in controls $(1.12 \mathrm{mmHg}$ [95\% CI $0.36,1.88]$; $p=0.004$; fixed-effect analysis; Fig. 6 b).

For both SBP and DBP, the difference between male ODM and male controls was greater than the difference between female ODM and female controls. The estimated differences, tested using meta-regression, were not significant for either SBP (difference $1.59 \mathrm{mmHg}$ [95\% CI -2.01, 5.18]; $p=0.33$ ) or DBP (difference $0.44 \mathrm{mmHg}$ [95\% CI $-1.63,2.52]$; $p=0.63$ ).

\section{a}

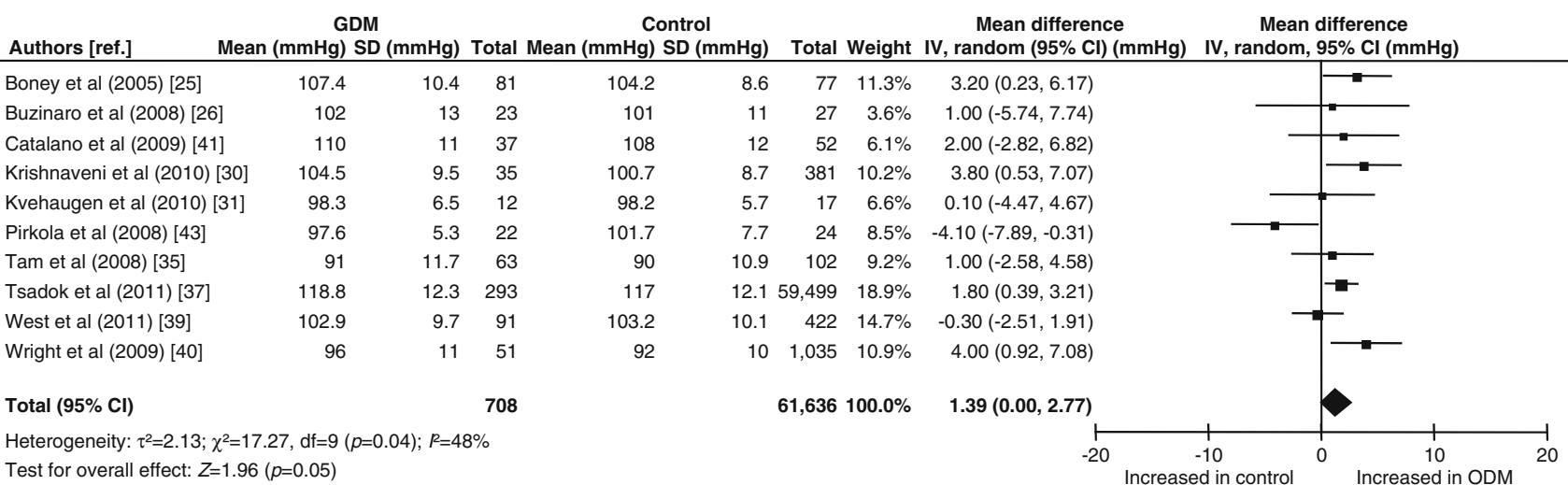

b

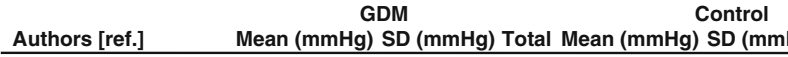

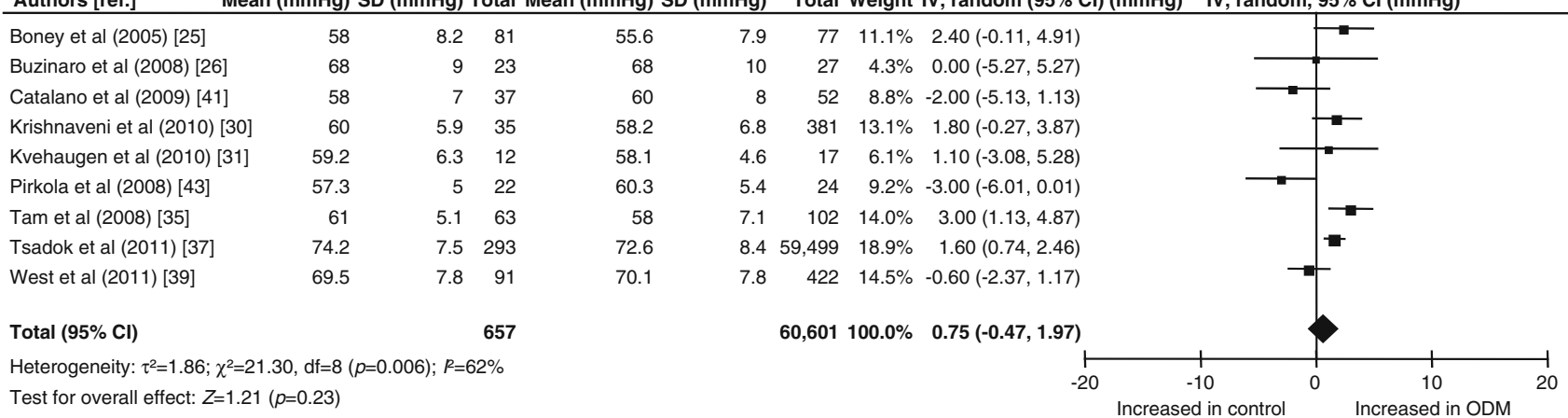

Fig. 3 Forest plot showing the unadjusted association between GDM and offspring BP. (a) SBP; (b) DBP. IV, inverse variance 
Author [ref.]

T1DM

Control

Mean difference

Mean difference

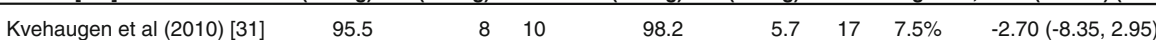

Manderson et al (2002) [33] $\quad 103.8 \quad 10.2 \quad 61 \quad 105.8 \quad 13.9 \quad 57 \quad 12.2 \% \quad-2.00(-6.42,2.42)$

Pirkola et al (2008) [43]

$101.5 \quad 7.2 \quad 16$

$\begin{array}{lr}7.2 & 16 \\ 8.2 & 213\end{array}$

101.7

$7.7 \quad 24 \quad 10.9 \%$

Rijpert et al (2011) [34]

100.2

101.7
96.9

$\begin{array}{lll}7.7 & 24 & 10.9 \% \\ 7.2 & 79 & 63.9 \%\end{array}$

$0.20(-4.88,4.48)$

West et al (2011) [39]

103.1

103.2

$10.1 \quad 422 \quad 5.5 \%$

$3.30(1.37,5.23)$

Total $(95 \% \mathrm{Cl})$

308

$599100.0 \% \quad 1.64(0.09,3.18)$

$-0.10(-6.68,6.48)$

Heterogeneity: $\chi^{2}=8.56, \mathrm{df}=4(p=0.07) ; R=53 \%$ IV, fixed (95\% Cl) (mmHg)

Test for overall effect: $Z=2.08(p=0.04)$

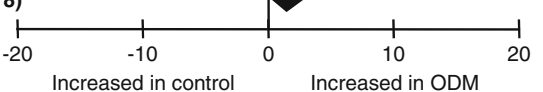

b

T1DM

Control

Mean difference

Mean difference

Author [ref.] Mean ( $\mathrm{mmHg}) \mathrm{SD}(\mathrm{mmHg})$ Total Mean $(\mathrm{mmHg})$ SD $(\mathrm{mmHg})$ Total Weight IV, random $(95 \% \mathrm{Cl})(\mathrm{mmHg}) \quad \mathrm{IV}, \mathrm{random},(95 \% \mathrm{Cl})(\mathrm{mmHg})$

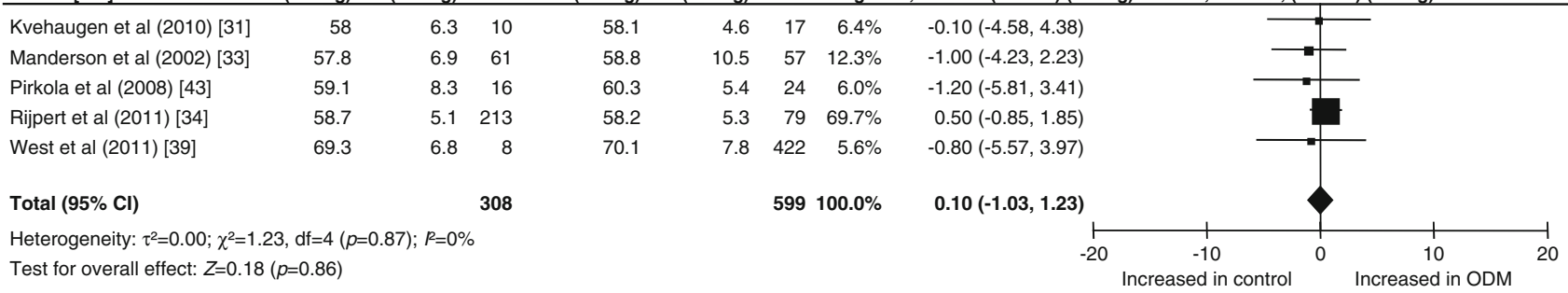

Fig. 4 Forest plot showing the unadjusted association between type 1 diabetes (T1DM) and offspring BP. (a) SBP; (b) DBP. IV, inverse variance

Heterogeneity

The following potential sources of heterogeneity other than type of maternal diabetes and offspring sex were investigated.

Study quality A meta-analysis limited to studies scoring $\geq 5$ out of 7 according to the Modified Newcastle-Ottawa Quality
Assessment Scale (seven studies for SBP [24, 29, 30, 33, 34, 36, 39], six studies for DBP [24, 29, 30, 33, 34, 36]) showed that both SBP and DBP were higher in ODM than in controls (SBP: $2.40 \mathrm{mmHg}$ [95\% CI 1.50, 3.31]; $p<0.00001$; fixed-effects analysis; ESM Fig. 3a. DBP: $1.54 \mathrm{mmHg}[95 \%$ CI 0.93, 2.15]; $p<0.00001$; fixed-effects analysis; ESM Fig. 3b).

a

\begin{tabular}{|c|c|c|c|c|c|c|c|c|c|c|}
\hline Author [ref.] & $\begin{array}{r}\text { Femal } \\
\text { Mean }(\mathrm{mmHg})\end{array}$ & $\begin{array}{l}\text { le ODM } \\
\text { SD }(\mathrm{mmHg})\end{array}$ & Total & $\begin{array}{r}\text { Female } \\
\text { Mean }(\mathrm{mmHg})\end{array}$ & $\begin{array}{l}\text { control } \\
\text { SD }(\mathrm{mmHg})\end{array}$ & Total & Weight & $\begin{array}{c}\text { Mean difference } \\
\text { IV, random }(95 \% \mathrm{Cl})(\mathrm{mmHg})\end{array}$ & $\begin{array}{r}\text { Mean dif } \\
\text { IV, random, } 95\end{array}$ & $\begin{array}{l}\text { ifference } \\
5 \% \mathrm{Cl}(\mathrm{mmHg})\end{array}$ \\
\hline Boney et al (2005) [25] & 102.2 & 11 & 35 & 103.6 & 8.5 & 37 & $10.4 \%$ & $-1.40(-5.96,3.16)$ & & \\
\hline Catalano et al (2009) [41] & 108 & 13 & 19 & 109 & 14 & 30 & $6.1 \%$ & $-1.00(-8.70,6.70)$ & & \\
\hline Krishnaveni et al (2010) [30] & 103.8 & 8 & 23 & 99.4 & 8.5 & 191 & $12.5 \%$ & $4.40(0.92,7.88)$ & & \\
\hline Kvehaugen et al (2010) [31] & 96.8 & 8.5 & 14 & 99.8 & 5.4 & 9 & $8.6 \%$ & $-3.00(-8.68,2.68)$ & & \\
\hline Pirkola et al (2008) [43] & 99.8 & 6 & 24 & 103.6 & 6.7 & 14 & $11.0 \%$ & $-3.80(-8.05,0.45)$ & & \\
\hline Rijpert et al (2011) [34] & 100.6 & 8.9 & 114 & 96.8 & 8.4 & 39 & $13.2 \%$ & $3.80(0.70,6.90)$ & & 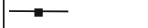 \\
\hline Tam et al (2008) [35] & 93 & 11.1 & 37 & 90 & 12.2 & 47 & $9.7 \%$ & $3.00(-2.00,8.00)$ & & 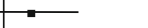 \\
\hline Tsadok et al (2011) [37] & 115.8 & 13 & 117 & 112.5 & 12.12 & 22,621 & $14.6 \%$ & $3.30(0.94,5.66)$ & & $\rightarrow$ \\
\hline West et al (2011) [39] & 99.8 & 8.4 & 46 & 102.7 & 9.6 & 215 & $13.9 \%$ & $-2.90(-5.65,-0.15)$ & & \\
\hline Total $(95 \% \mathrm{Cl})$ & & & 429 & & & 23,203 & $100.0 \%$ & $0.54(-1.83,2.90)$ & & \\
\hline \multicolumn{4}{|c|}{$\begin{array}{l}\text { Heterogeneity: } \tau^{2}=8.49 ; \chi^{2}=26.92, d f=8(p=0.0007) ; R=70 \% \\
\text { Test for overall effect: } Z=0.45(p=0.66)\end{array}$} & \multicolumn{5}{|r|}{-20} & \multicolumn{2}{|c|}{$0 \quad 10$} \\
\hline
\end{tabular}

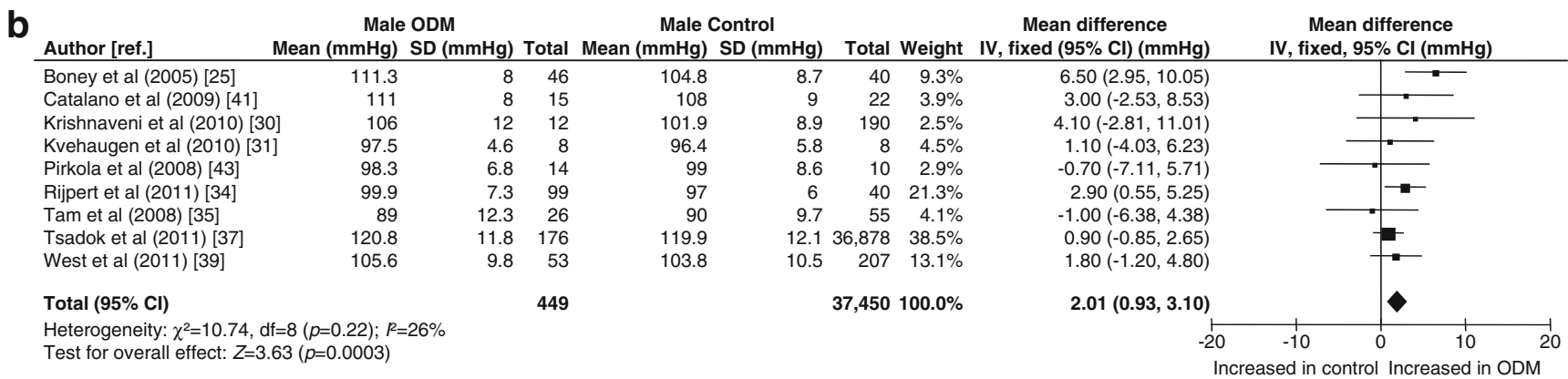

Fig. 5 Forest plot showing the unadjusted association between all types of maternal diabetes and offspring systolic BP, according to sex. (a) Female offspring; (b) male offspring. IV, inverse variance 


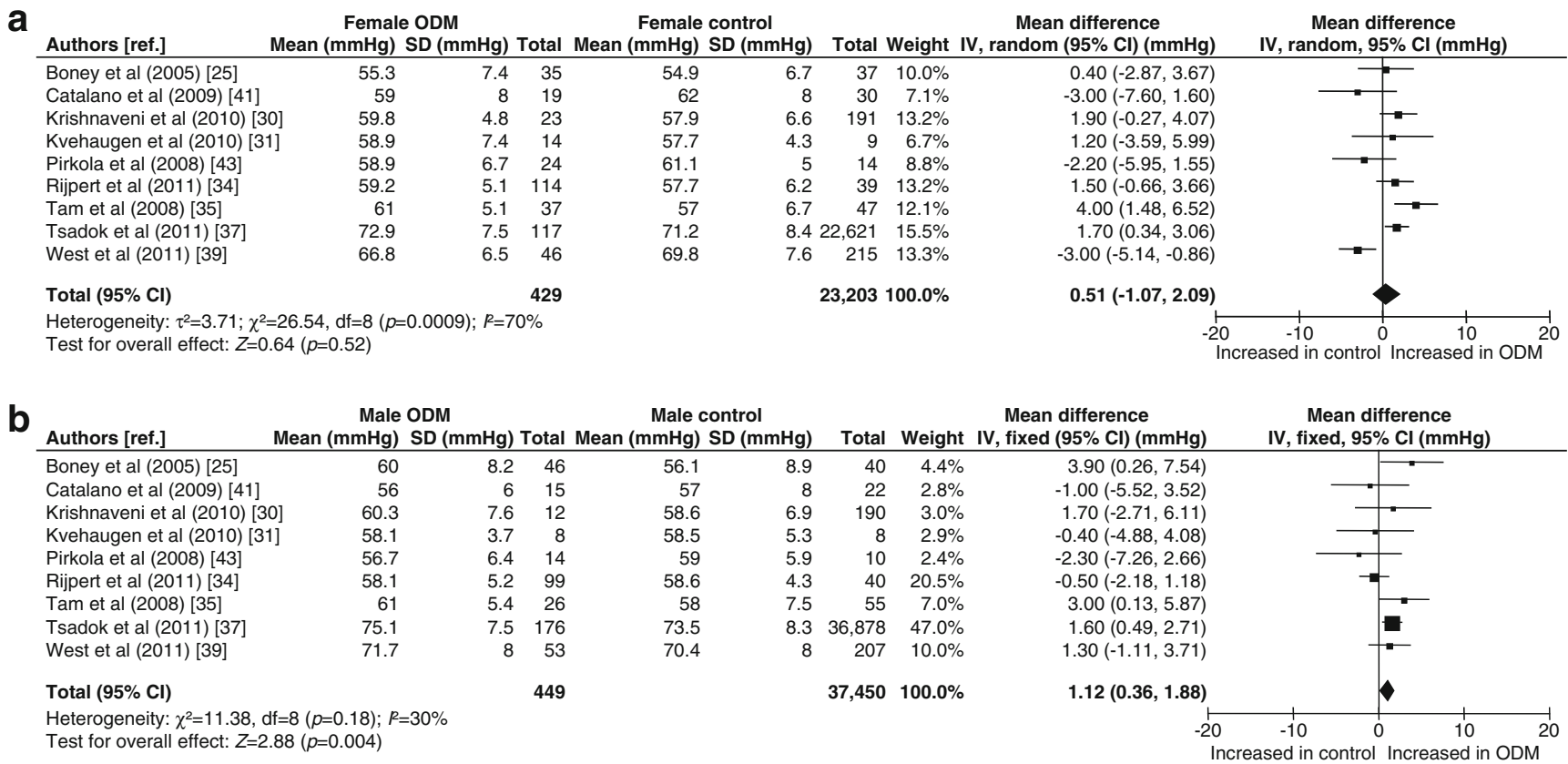

Fig. 6 Forest plot showing the unadjusted association between all types of maternal diabetes and offspring diastolic BP, according to sex. (a) Female offspring; (b) male offspring. IV, inverse variance

Adjusted analyses In five studies, SBP was adjusted for covariates including offspring sex and age $[33,34,36,38$, 39]. A meta-analysis of the adjusted data showed that SBP was higher in ODM than controls $(2.43 \mathrm{mmHg}$ [95\% CI 0.90, 3.97]; $p=0.002$; random-effects analysis; ESM Fig. 4a). A meta-analysis of the unadjusted data from these five studies showed higher SBP in ODM $(1.89 \mathrm{mmHg}$ [95\% CI 0.97, 2.81]; $p<0.0001$; fixed-effects analysis: $I^{2} 51 \% ; p=0.08$ ).

Three of the five studies provided data for DBP adjusted for covariates including offspring sex and age [33, 34, 36]. A meta-analysis of the adjusted data showed no

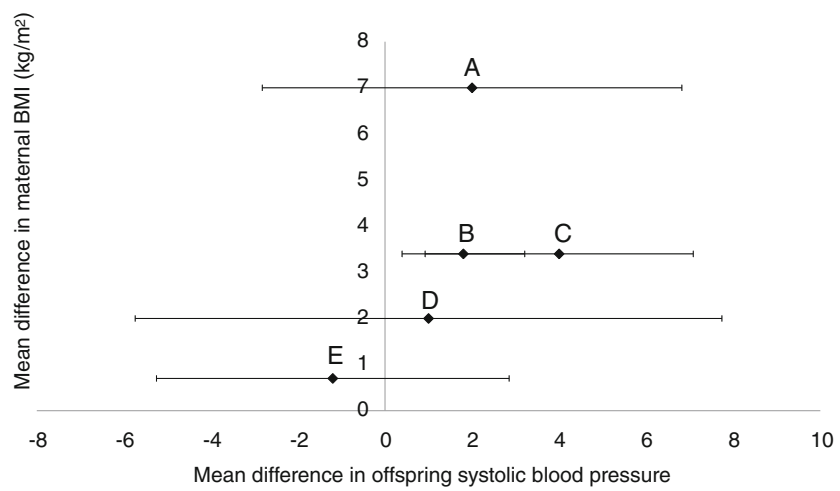

Fig. 7 Relationship between the mean difference in maternal BMI between diabetic and non-diabetic mothers and the mean difference between SBP of offspring of diabetic and non-diabetic mothers. Letters represent the following studies: A, Catalano et al (2009) [40]; B, Tsadok et al (2011) [36]; C, Wright et al (2009) [39]; D, Buzinaro et al (2008) [25]; E, Kvehaugen et al (2010) [30] difference in DBP between ODM and controls $(-0.77 \mathrm{mmHg}$ [95\% CI $-3.85,2.31] ; p=0.62$; random-effects analysis; ESM Fig. 4b). A meta-analysis of the unadjusted data from these three studies showed higher DBP in ODM $(1.51 \mathrm{mmHg}$ [95\% CI 0.83, 2.19]; $p<0.0001$; fixed-effects analysis: $\left.I^{2} 57 \% ; p=0.10\right)$.

Maternal prepregnancy BMI Only two studies reported offspring BP data adjusted for maternal prepregnancy BMI, so no meta-analysis was performed in this subgroup [38, 39]. Five studies provided prepregnancy BMI data $[25,30,36$, 39, 40]; for these studies the mean difference in maternal prepregnancy BMI was plotted against the mean difference in offspring SBP (Fig. 7). This analysis suggests that, as the difference in maternal BMI between the diabetic and nondiabetic groups reduces, so too does the difference in offspring SBP; however, this relationship was not statistically significant $(p=0.37)$.

\section{Discussion}

In this systematic review and meta-analysis, we show an association between exposure to maternal diabetes in utero and increased offspring SBP in childhood. However, subgroup analyses show the association between maternal diabetes and both SBP and DBP to be significant in male offspring, but not in female offspring. There is some evidence that the 
association between maternal diabetes and offspring SBP may be influenced by maternal prepregnancy BMI.

Our primary analyses showed high heterogeneity; possible explanations for this include type of maternal diabetes, sex and study quality. Subgroup analysis according to type of maternal diabetes demonstrates significant heterogeneity in studies reporting outcomes for offspring of mothers with GDM. This may be due to the variable definition used across studies (Table 1), which can impact on the reported population prevalence of GDM [43]. Three studies define GDM using the Carpenter and Coustan diagnostic criteria (lower threshold than the National Diabetes Data Group) $[24,29,39]$; all found greater systolic BP in ODM. Inclusion of studies using lower threshold criteria for GDM diagnosis may affect the magnitude of the effect seen, but long-term effects probably occur across the range of maternal glucose intolerance [44]. Differences in treatment of GDM and variation in glycaemic control achieved may also drive heterogeneity [45]. Unfortunately, most studies on the outcome of diabetic pregnancies fail to adequately describe the treatment used in their diabetic group.

The lack of significant heterogeneity in studies reporting BP in offspring of mothers with type 1 diabetes may be related to the small number of studies. For SBP, the pooled result in the random-effects analysis was smaller in magnitude and no longer significant. These findings make it difficult to draw conclusions on the magnitude of the effect of type 1 diabetes on offspring BP. Prepregnancy type 2 diabetes accounts for $\sim 5 \%$ of diabetic pregnancies [1]; no studies were identified reporting BP in the offspring of these pregnancies. However, long-term effects of exposure to diabetes in utero are similar regardless of diabetes type $[46,47]$. Effects of intrauterine exposure to prepregnancy type 2 diabetes on childhood BP should be assessed in future studies.

Sex-specific effects of maternal diabetes on the offspring may also explain the heterogeneity. Although the difference in effect between the sexes was not statistically significant, the effect does appear to be larger and more consistent in male offspring for both SBP and DBP. The confidence intervals for the female subgroups are not close around zero, and so do not support a lack of effect. Plausibly, a smaller effect exists in female offspring, detection of which would be complicated by the increased heterogeneity in this subgroup. Of note, the sex subgroup analyses included the same studies, with comparable population sizes, so differences observed cannot be attributed to study characteristics. The meta-regression potentially lacked power to detect sex differences, demonstrated by the wide confidence intervals. However, the different effect of maternal diabetes on BP in male and female offspring is consistent with the well-known sex disparity in the epidemiology, evolution and prognosis of cardiovascular disease, including hypertension [12], the main explanation for which is related to the protective effect of endogenous oestrogens on BP regulation [48]. However, recent data question the protective role of female sex. We recently showed in individuals born preterm that women have higher BP than men [49]. The INTERHEART study has shown that young women have the highest risk of acute myocardial infarction related to features of the metabolic syndrome [50]. As our meta-analysis included studies with participants spanning pubertal development, this may offer further explanation for the heterogeneity in the female subgroup, as major changes in oestrogen profile occur during the pubertal period. Furthermore, the menstrual cycle influences BP [51], and no studies reported controlling for menstrual cycle.

Study quality represents another potential source of heterogeneity; when the analysis was restricted to higherquality studies, heterogeneity was minimal and the association between maternal diabetes and SBP appeared stronger. The association between maternal diabetes and DBP was significant in this analysis, suggesting that the poor methodological quality of some studies may explain the lack of a significant effect on DBP in the overall analysis. This is supported by the funnel plots, which showed that estimates from studies with larger standard errors are in the opposite direction to the pooled result, so any bias is attenuating rather than accentuating our findings. From Egger's test, no evidence of asymmetry was shown for either SBP or DBP, and this is suggestive of low risk of publication bias. However, this finding should be interpreted with caution, as Egger's test lacks power when there are few studies [21]. The two significant factors reducing the study quality score were a lack of adjustment for offspring sex and size (weight/height/BMI) at time of assessment (see ESM Fig. 5). Both these factors significantly impact on BP and should be adjusted for [52]. Also, few studies reported the use of blinded assessors when measuring BP. These factors should be considered in the design of future studies in this field. Selection of high-quality studies for use in meta-analyses is vital to ensure the reliability of the pooled results.

To date, most studies of the biological pathways linking hyperglycaemia in utero and offspring BP have been conducted in animal models. Low nephron number is a powerful predictor of adult hypertension [53, 54], and adults with primary hypertension have fewer nephrons than normotensive controls [55]. Nephron count is $13-22 \%$ lower in rats born to diabetic mothers [56]. Hyperglycaemia during pregnancy alters fetal vascular development through abnormal signalling of the vascular endothelial growth factor-A [57] and increased plasma concentrations of markers of vascular inflammation $[32,38]$. At birth, umbilical cord C-peptide concentrations correlate positively with indexes of arterial stiffness [58], an independent predictor of cardiovascular 
risk, playing a role in the development of isolated systolic hypertension [59].

It is plausible that the risk of developing features of the metabolic syndrome in the offspring is related to the intrauterine exposure to a hyperglycaemic environment, independently of other risk factors such as gene determinants. Data from studies in Pima Indians support this contention, as these show that, despite a genetic predisposition to obesity and diabetes, offspring born before the onset of maternal diabetes have lower childhood BP [11] and BMI $z$ score [60] than siblings born after the onset of maternal diabetes.

The association between offspring BP and maternal diabetes appears to be influenced by maternal prepregnancy BMI, and this is consistent with our report that the association between diabetes during pregnancy and offspring BMI is weakened when adjusted for maternal prepregnancy BMI [61]. The association between maternal BMI and offspring BP suggests that maternal hyperglycaemia of lesser degree than in overt diabetes, for which BMI is a proxy, influences offspring BP. This hypothesis is consistent with the findings of the primary analysis of the HAPO Study, which showed a continuous association between maternal glucose levels, even below those diagnostic of diabetes, and adverse neonatal outcomes [45]. In the same cohort, GDM and maternal obesity during pregnancy were independently associated with adverse pregnancy outcomes, including increased birthweight, cord blood C-peptide and offspring body fat, and the combination of these two factors had a greater impact than either one alone [5]. Follow-up of the HAPO Study has not yet provided data on offspring BP. In our meta-analysis, a trend was observed when the difference in maternal prepregnancy BMI between ODM and control groups was plotted against the difference in SBP, but there was no statistically significant difference when examined using meta-regression; however, this test had low power, as there were only five studies. Offspring SBP data adjusted for maternal prepregnancy BMI are reported in only two studies. West et al found that the association was no longer significant [38] when BP data from ODM were adjusted for maternal prepregnancy BMI. Conversely, Wright et al reported that adjustment for several variables including maternal prepregnancy BMI did not change the association between exposure to maternal diabetes and offspring SBP [39].

It is possible that offspring BMI mediates the increase in offspring BP. Offspring BP data adjusted for offspring BMI were reported in only two studies. Rijpert et al found that adjustment for BMI did not change the significance of the difference in SBP between ODM and controls [33], while West et al found attenuation of the relationship between maternal diabetes and offspring SBP when adjusted for offspring BMI [38]. However, adjustment in this way may be inadvisable [62], as offspring BMI is potentially on the causal pathway linking the in utero diabetic environment and increased offspring BP. As it is not known how or if offspring BMI mediates the relationship between maternal diabetes and offspring BP, and given that only aggregate data were available to us, we were unable to explore the possibility of an independent effect of maternal diabetes and offspring BMI on offspring BP. Future studies examining the relationship between maternal diabetes and offspring BP must include collection of data on all potential confounding factors and mediators, and statistical analyses should be carried out with regard to the causal framework.

Conclusions drawn from meta-analyses of observational studies may be misleading [63]. Methods used for BP measurement varied among studies in our meta-analysis; they included manual sphygmomanometers, as well as automated devices, which have the advantage of achieving high-quality BP determinations by reducing observer errors [64]. In three studies, the method used for BP measurement was not stated. The age range in which offspring BP was measured also varied widely, and was not adjusted for in the individual studies; this potential limitation has been partially overcome by performing a meta-analysis of offspring BP data adjusted for age and sex, which still shows a significant increase in SBP in ODM compared with controls. Including studies in our primary analysis in which the diabetic population was selective (i.e. only mothers with type 1 diabetes), and thus not reflective of the spectrum of diabetes in the general population, may limit the generalisability of the findings of our primary analysis to the general obstetric population. However, given that we found no significant difference in effect dependent on type of maternal diabetes, this confounding is likely to be small.

Our findings have important implications. Children with high SBP are likely to have increased risk of hypertension in adulthood [65]. Hypertension is a significant risk factor for cardiovascular disease [66], with a linear association between SBP, DBP and cardiovascular morbidity and mortality [67]. Consequently, even small differences in BP, such as we have described, may have important population-health implications. Estimates suggest that every $2 \mathrm{mmHg}$ rise in SBP is associated with a $7 \%$ increased risk of mortality from ischaemic heart disease and a $10 \%$ increased risk of mortality from stroke [68]. Consequently, it is important to consider whether the long-term effects of intrauterine exposure to diabetes are potentially ameliorable. Animal models demonstrate that strict glycaemic control during pregnancy is essential for optimal kidney growth and development during fetal life [56]. The HAPO Study showed that maternal glucose concentrations below those considered as diagnostic for diabetes are also associated with adverse infant outcomes, suggesting that current criteria for diagnosing and treating hyperglycaemia during pregnancy need to be reconsidered [45]. A key research question now is whether strict glycaemic control during pregnancy could modify the effect of maternal diabetes on offspring BP. 
Acknowledgements We would like to thank all the authors listed in Table 1 who kindly contributed additional data to this meta-analysis.

Funding M.J. Hyde is funded by Chelsea \& Westminster NHS Foundation Trust. C. Gale is supported by Chelsea and Westminster Health Charity. K.M. Logan received support from Chelsea and Westminster Health Charity and is currently funded by a fellowship from Action Medical Research. S. Santhakumaran is funded through a National Institute of Health Research programme grant held by $\mathrm{N}$. Modi. No external funding was received specifically for this work.

Duality of interest N. Modi has received consultancy fees from Ferring Pharmaceuticals; she declares no other duality of interest. The other authors declare that they have no duality of interest associated with this manuscript.

Contribution statement The study was conceived and supervised by MJH, KML and NM. LHP conducted the literature search, assisted by $\mathrm{EP}$ and $\mathrm{MJH}$; where required $\mathrm{MJH}$ and $\mathrm{AA}$ contacted the authors for further data; LHP and MJH extracted the data from the relevant papers, checked by KML and AA. AA, CG and MJH carried out a quality assessment of all included studies. LHP, AA, MJH and SS conducted the meta-analysis. AA, MJH and CG wrote the first draft of the paper. This was revised by NM. All authors contributed to interim and final drafts of the paper. All authors saw and approved the final version of the paper for submission. NM made the final decision to submit the paper for publication.

\section{References}

1. NICE (2009) NICE guideline 63: diabetes in pregnancy. Management of diabetes and its complications in pregnancy from the preconception to the postnatal period. In, www.nice.org.uk/CG063, accessed 3 August 2012

2. Bell R, Bailey K, Cresswell T, Hawthorne G, Critchley J, LewisBarned N (2008) Trends in prevalence and outcomes of pregnancy in women with pre-existing type I and type II diabetes. BJOG 115:445-452

3. Dabelea D, Snell-Bergeon JK, Hartsfield CL, Bischoff KJ, Hamman RF, McDuffie RS (2005) Increasing prevalence of gestational diabetes mellitus (GDM) over time and by birth cohort: Kaiser Permanente of Colorado GDM Screening Program. Diabetes Care 28:579-584

4. Weindling AM (2009) Offspring of diabetic pregnancy: short-term outcomes. Semin Fetal Neonatal Med 14:111-118

5. Catalano PM, McIntyre HD, Cruickshank JK et al (2012) The hyperglycemia and adverse pregnancy outcome study: associations of GDM and obesity with pregnancy outcomes. Diabetes Care 35:780-786

6. Simeoni U, Barker D (2009) Offspring of diabetic pregnancy: long-term outcomes. Semin Fetal Neonatal Med 14:119

7. Freinkel N (1980) Banting Lecture 1980. Of pregnancy and progeny. Diabetes 29:1023

8. Freinkel N, Metzger BE (1978) Pregnancy as a tissue culture experience: the critical implications of maternal metabolism for fetal development. Ciba Found Symp: 3-28

9. Franks PW, Hanson RL, Knowler WC, Sievers ML, Bennett PH, Looker HC (2010) Childhood obesity, other cardiovascular risk factors, and premature death. N Engl J Med 362:485-493

10. Pettitt DJ, Aleck KA, Baird HR, Carraher MJ, Bennett PH, Knowler WC (1988) Congenital susceptibility to NIDDM. Role of intrauterine environment. Diabetes 37:622
11. Bunt JC, Tataranni PA, Salbe AD (2005) Intrauterine exposure to diabetes is a determinant of hemoglobin $\mathrm{A}(1) \mathrm{c}$ and systolic blood pressure in Pima Indian children. J Clin Endocrinol Metab 90:32253229

12. Vitale C, Mendelsohn ME, Rosano GM (2009) Gender differences in the cardiovascular effect of sex hormones. Nat Rev Cardiol 6:532-542

13. Stroup DF, Berlin JA, Morton SC et al (2000) Meta-analysis of observational studies in epidemiology: a proposal for reporting. Meta-analysis of Observational Studies in Epidemiology (MOOSE) group. JAMA 283:2008-2012

14. Wells GA, Shea B, O'Connell D, et al. The Newcastle-Ottawa Scale (NOS) for assessing the quality of nonrandomised studies in metaanalyses. In, http://www.ohri.ca/programs/clinical_epidemiology/ oxford.asp, accessed 3 August 2012

15. Hedges LV, Tipton E, Johnson MC (2010) Robust variance estimation in meta-regression with dependent effect size estimates. Res Synth Meth 1:39-65

16. Cochran WG (1954) The combination of estimates from different experiments. Biometrics 10:101-129

17. Higgins JP, Thompson SG (2002) Quantifying heterogeneity in a meta-analysis. Stat Med 21:1539-1558

18. Cochrane Handbook for Systematic Reviews of Interventions. Version 5.1.0 (March 2011). In: Higgins JPT, Green S (eds) The Cochrane Collaboration, 2011

19. Hardy RJ, Thompson SG (1998) Detecting and describing heterogeneity in meta-analysis. Stat Med 17:841-856

20. Poole C, Greenland S (1999) Random-effects meta-analyses are not always conservative. Am J Epidemiol 150:469-475

21. Egger M, Davey Smith G, Schneider M, Minder C (1997) Bias in meta-analysis detected by a simple, graphical test. BMJ 315:629-634

22. Belfort MB, Gillman MW, McCormick MC (2012) Prenatal and perinatal predictors of blood pressure at school age in former preterm, low birth weight infants. J Perinatol 32:265-269

23. Nelson RG, Morgenstern H, Bennett PH (1998) Intrauterine diabetes exposure and the risk of renal disease in diabetic Pima Indians. Diabetes 47:1489-1493

24. Boney CM, Verma A, Tucker R, Vohr BR (2005) Metabolic syndrome in childhood: association with birth weight, maternal obesity, and gestational diabetes mellitus. Pediatrics 115:e290-e296

25. Buzinaro EF, Berchieri CB, Haddad AL, Padovani CR, Pimenta Wde $\mathrm{P}$ (2008) Overweight in adolescent offspring of women with hyperglycemia during pregnancy. Arq Bras Endocrinol Metabol 52:85-92

26. Calabrese S, Giansante C, Burigana F, Feruglio FS (1981) Platelet factor 3 and 4 in juvenile diabetes and in children of diabetic mothers. Minerva Med 72:2255-2260

27. Charles MA, Pettitt DJ, Hanson RL et al (1994) Familial and metabolic factors related to blood pressure in Pima Indian children. Am J Epidemiol 140:123-131

28. Cho NH, Silverman BL, Rizzo TA, Metzger BE (2000) Correlations between the intrauterine metabolic environment and blood pressure in adolescent offspring of diabetic mothers. J Pediatr 136:587

29. Krishnaveni GV, Veena SR, Hill JC, Kehoe S, Karat SC, Fall CH (2010) Intrauterine exposure to maternal diabetes is associated with higher adiposity and insulin resistance and clustering of cardiovascular risk markers in Indian children. Diabetes Care 33:402-404

30. Kvehaugen AS, Andersen LF, Staff AC (2010) Anthropometry and cardiovascular risk factors in women and offspring after pregnancies complicated by preeclampsia or diabetes mellitus. Acta Obstet Gynecol Scand 89:1478-1485

31. Lee H, Jang HC, Park HK, Cho NH (2007) Early manifestation of cardiovascular disease risk factors in offspring of mothers with previous history of gestational diabetes mellitus. Diabetes Res Clin Pract 78:238-245

32. Manderson JG, Mullan B, Patterson CC, Hadden DR, Traub AI, McCance DR (2002) Cardiovascular and metabolic abnormalities in the offspring of diabetic pregnancy. Diabetologia 45:991-996 
33. Rijpert M, Evers IM, de Valk HW et al (2011) Cardiovascular and metabolic outcome in 6-8 year old offspring of women with type 1 diabetes with near-optimal glycaemic control during pregnancy. Early Hum Dev 87:49-54

34. Tam WH, Ma RC, Yang X et al (2008) Glucose intolerance and cardiometabolic risk in children exposed to maternal gestational diabetes mellitus in utero. Pediatrics 122:1229-1234

35. Tam WH, Ma RC, Yang X et al (2010) Glucose intolerance and cardiometabolic risk in adolescents exposed to maternal gestational diabetes: a 15-year follow-up study. Diabetes Care 33:1382-1384

36. Tsadok MA, Friedlander Y, Paltiel O et al (2011) Obesity and blood pressure in 17-year-old offspring of mothers with gestational diabetes: insights from the Jerusalem Perinatal Study. Exp Diabetes Res 2011:906154

37. Vohr BR, McGarvey ST, Tucker R (1999) Effects of maternal gestational diabetes on offspring adiposity at 4-7 years of age. Diabetes Care 22:1284-1291

38. West NA, Crume TL, Maligie MA, Dabelea D (2011) Cardiovascular risk factors in children exposed to maternal diabetes in utero. Diabetologia 54:504-507

39. Wright CS, Rifas-Shiman SL, Rich-Edwards JW, Taveras EM, Gillman MW, Oken E (2009) Intrauterine exposure to gestational diabetes, child adiposity, and blood pressure. Am J Hypertens 22:215-220

40. Catalano PM, Farrell K, Thomas A et al (2009) Perinatal risk factors for childhood obesity and metabolic dysregulation. Am J Clin Nutr 90:1303-1313

41. Lindsay RS, Nelson SM, Walker JD et al (2010) Programming of adiposity in offspring of mothers with type 1 diabetes at age 7 years. Diabetes Care 33:1080-1085

42. Pirkola J, Vaarasmaki M, Leinonen E et al (2008) Maternal type 1 and gestational diabetes: postnatal differences in insulin secretion in offspring at preschool age. Pediatr Diabetes 9:583-589

43. Karcaaltincaba D, Kandemir O, Yalvac S, Guvendag-Guven S, Haberal A (2009) Prevalence of gestational diabetes mellitus and gestational impaired glucose tolerance in pregnant women evaluated by National Diabetes Data Group and Carpenter and Coustan criteria. Int J Gynaecol Obstet 106:246-249

44. Hillier T, Pedula K, Schmidt M, Mullen J, Charles M-A, Pettitt D (2007) Childhood obesity and metabolic imprinting: the ongoing effects of maternal hyperglycemia. Diabetes Care 30:2287

45. Metzger BE, Lowe LP, Dyer AR et al (2008) Hyperglycemia and adverse pregnancy outcomes. N Engl J Med 358:1991-2002

46. Dabelea D (2007) The predisposition to obesity and diabetes in offspring of diabetic mothers. Diabetes Care 30(Supp1 2):S169-S174

47. Silverman BLMBE, Cho NH, Loeb CA (1995) Impaired glucose tolerance in adolescent offspring of diabetic mothers. Relationship to fetal hyperinsulinism. Diabetes care 18:611-617

48. Dubey RK, Oparil S, Imthurn B, Jackson EK (2002) Sex hormones and hypertension. Cardiovasc Res 53:688-708

49. Parkinson JRC, Hyde MJ, Gale C, Santhakumaran S, Modi N (2011) Preterm birth and adult blood pressure: a meta-analysis. In: Neonatal Society Meeting, http://www.neonatalsociety.ac.uk/ meetings/2011_autumn_abstracts.pdf: p. 9

50. Mente A, Yusuf S, Islam S et al (2010) Metabolic syndrome and risk of acute myocardial infarction a case-control study of 26,903 subjects from 52 countries. J Am Coll Cardiol 55:2390-2398
51. Dunne FP, Barry DG, Ferriss JB, Grealy G, Murphy D (1991) Changes in blood pressure during the normal menstrual cycle. Clin Sci (Lond) 81:515-518

52. He Q, Ding ZY, Fong DYT, Karlberg J (2000) Blood pressure is associated with body mass index in both normal and obese children. Hypertension 36:165-170

53. Brenner BM, Garcia DL, Anderson S (1988) Glomeruli and blood pressure. Less of one, more the other? Am J Hypertens 1:335-347

54. Ritz E, Amann K, Koleganova N, Benz K (2011) Prenatal programming-effects on blood pressure and renal function. Nat Rev Nephrol 7:137-144

55. Keller G, Zimmer G, Mall G, Ritz E, Amann K (2003) Nephron number in patients with primary hypertension. $\mathrm{N}$ Engl $\mathrm{J}$ Med 348:101-108

56. Amri K, Freund N, Vilar J, Merlet-Benichou C, LelievrePegorier M (1999) Adverse effects of hyperglycemia on kidney development in rats: in vivo and in vitro studies. Diabetes 48:2240 2245

57. Pinter E, Haigh J, Nagy A, Madri JA (2001) Hyperglycemiainduced vasculopathy in the murine conceptus is mediated via reductions of VEGF-A expression and VEGF receptor activation. Am J Pathol 158:1199-1206

58. Tam WH, Ma RC, Yip GW et al (2012) The association between in utero hyperinsulinemia and adolescent arterial stiffness. Diabetes Res Clin Pract 95:169-175

59. Franklin SS (2008) Beyond blood pressure: arterial stiffness as a new biomarker of cardiovascular disease. J Am Soc Hypertens 2:140-151

60. Dabelea D, Hanson RL, Lindsay RS et al (2000) Intrauterine exposure to diabetes conveys risks for type 2 diabetes and obesity: a study of discordant sibships. Diabetes 49:2208-2211

61. Philipps LH, Santhakumaran S, Gale C et al (2011) The diabetic pregnancy and offspring BMI in childhood: a systematic review and meta-analysis. Diabetologia 54:1957-1966

62. Robins JM, Greenland S (1992) Identifiability and exchangeability for direct and indirect effects. Epidemiology 3:143-155

63. Walker E, Hernandez AV, Kattan MW (2008) Meta-analysis: its strengths and limitations. Cleve Clin J Med 75:431-439

64. Graves JW, Althaf MM (2006) Utility of ambulatory blood pressure monitoring in children and adolescents. Pediatr Nephrol 21:1640-1652

65. Sun SS, Grave GD, Siervogel RM, Pickoff AA, Arslanian SS, Daniels SR (2007) Systolic blood pressure in childhood predicts hypertension and metabolic syndrome later in life. Pediatrics 119:237-246

66. Roger VL, Go AS, Lloyd-Jones DM et al (2012) Heart disease and stroke statistics - 2012 update: a report from the American Heart Association. Circulation 125:e2-e220

67. Kannel WB, Vasan RS, Levy D (2003) Is the relation of systolic blood pressure to risk of cardiovascular disease continuous and graded, or are there critical values? Hypertension 42:453-456

68. NICE (2011) NICE guideline 127: Hypertension: Clinical management of primary hypertension in adults In, www.nice.org.uk/ guidance/CG127, accessed 3 August 2012

69. Catalano PM, Thomas A, Huston-Presley L, Amini SB (2003) Increased fetal adiposity: a very sensitive marker of abnormal in utero development. Am J Obstet Gynecol 189:1698-1704 